\title{
Transient QT Interval Prolongation With Inverted T Waves Indicates Myocardial Salvage on Dual Radionuclide Single-Photon Emission Computed Tomography in Acute Anterior Myocardial Infarction
}

\author{
Tohru Obayashi, MD; Takeshi Tokunaga, MD; Tomohiro Iiizumi, MD; \\ Tatsuo Shiigai, MD; Michiaki Hiroe, MD*; Fumiaki Marumo, MD*
}

\begin{abstract}
In patients with acute myocardial infarction (AMI), transient QT interval prolongation with a prominent negative $\mathrm{T}$ wave is frequently observed in cases of early spontaneous reperfusion and often indicates a good prognosis. Additionally, in nuclear cardiac imaging, technetium-99m/thallium-201 overlap on dual single-photon emission computed tomography (dual SPECT) in AMI patients indicates the presence of viable myocardium and early recanalization. To elucidate the clinical significance of this transient QT interval prolongation, 34 patients $(64 \pm 8$ years) admitted within $24 \mathrm{~h}$ of the onset of anterior AMI were enrolled and classified into 2 groups according to the presence (group A, $n=24$ ) or absence (group $B, n=10$ ) of scintigraphic overlap on simultaneous dual SPECT imaging. The maximal QTc interval was $0.59 \pm 0.06 \mathrm{~s}$ in group A and $0.52 \pm 0.06 \mathrm{~s}$ in group $\mathrm{B}(\mathrm{p}<0.01)$. The peak creatine kinase was lower in group A $(2650 \pm 2160 \mathrm{IU} / \mathrm{L})$ than in group B $(3490 \pm 2060 \mathrm{IU} / \mathrm{L})$. The left ventricular ejection fraction (LVEF) at discharge was $62 \pm 11 \%$ in group $A$ and $49 \pm 14 \%$ in group $B(p<0.01)$. The scintigraphic overlap group had a smaller infarct and better LVEF, which suggests that the QT interval prolongation that appears transiently in the acute phase of AMI indicates scintigraphically the presence of salvaged myocardium. (Jpn Circ J 2001; 65: 7-10)
\end{abstract}

Key Words: Acute myocardial infarction; Dual SPECT (dual single-photon emission computed tomography); Scintigraphic overlap; Transient QT interval prolongation

$\mathbf{I}$ n patients with acute myocardial infarction (AMI), QT interval prolongation is commonly seen when standard 12-lead ECG are serially recorded ${ }^{1-3}$ and is characteristically transient (36-48 $\mathrm{h}$ after the onset of AMI) and associated with a prominent negative T wave4 QT prolongation has been considered a poor prognostic sign leading to ventricular tachycardia or sudden cardiac death, 5,6 but it is frequently observed in cases of early spontaneous reperfusion and often indicates a good prognosis. Nuclear imaging in the early post-infarction period is useful in estimating the extent of myocardial salvage, $, 9,14$ but there are few previous reports on the relation between this transient ECG change and the scintigraphy findings during the acute phase of AMI? The present study aimed to elucidate the clinical significance of transient QT interval prolongation with a prominent negative T wave, using scintigraphic technetium- $99 \mathrm{~m}\left({ }^{99 \mathrm{mTc}}\right)$ pyrophosphate/thallium-201 $\left.{ }^{(201} \mathrm{Tl}\right)$ chloride dual single-photon emission computed tomography (dual SPECT)?

\section{Methods}

\section{Patient Selection}

Of 154 consecutive survivors of AMI evaluated during a

(Received June 5, 2000; revised manuscript received October 10, 2000; accepted October 11, 2000)

Department of Internal Medicine, Toride Kyodo General Hospital and $*$ Second Department of Internal Medicine, Tokyo Medical and Dental University, Tokyo, Japan

Mailing address: Tohru Obayashi, MD, Department of Internal Medicine, Toride Kyodo General Hospital, 2-1-1 Hongo, Toride, Ibaraki 302-0022, Japan 30-month period, 34 patients who had been admitted within $24 \mathrm{~h}$ of onset of first anterior AMI, had maintained sinus rhythm without bundle branch block and who had undergone dual SPECT, were enrolled in this study. The diagnosis of AMI was based on typical chest pain lasting more than $30 \mathrm{~min}$ with ST-segment elevation of $>0.2 \mathrm{mV}$ in at least 2 continuous precordial leads on ECG and an increase in serum creatine kinase to at least twice the upper level of normal. Patients with severe congestive heart failure and those who had been given cathecholamines were excluded. There were 25 men and 9 women, with a mean age of $64 \pm 8$ years (range, 49-81). Of these 34 patients, 30 underwent coronary angiography: 21 had single-vessel coronary artery disease (CAD), 3 had double-vessel CAD and 6 had triplevessel CAD. The patients were classified into 2 groups according to the presence (group A, n=24) or absence (group $\mathrm{B}, \mathrm{n}=10$ ) of scintigraphic overlap on simultaneous dual SPECT imaging, on the basis that previous reports have suggested that the overlap phenomenon indicates the presence of viable myocardium $4,14,15$

\section{ECG Recording}

Standard 12-lead ECGs were serially recorded every $6 \mathrm{~h}$ after admission for 2 days, every $12 \mathrm{~h}$ for the next 2 days, every $24 \mathrm{~h}$ for the following 3 days, 2 weeks later and just before discharge. The QT and RR interval were measured in 3 consecutive beats; the QTc was obtained from the Bazzet's formula: QTc $=\mathrm{QT} / \sqrt{\mathrm{RR}} ! 0,11$ The QT interval was measured in each lead from the onset of QRS to the end of the T wave on the isoelectric baseline. The end of the $\mathrm{T}$ wave was defined as return to the isoelectric baseline. When the $\mathrm{U}$ 
Table 1 Patient Characteristics

\begin{tabular}{lccc}
\hline \hline Overlap & $\begin{array}{c}\text { Group } A(+) \\
(n=24)\end{array}$ & $\begin{array}{c}\text { Group B }(-) \\
(n=10)\end{array}$ & p value \\
\hline Age $($ years $)$ & $65.3 \pm 8.3$ & $59.2 \pm 6.6$ & $<0.05$ \\
$($ age $>70$ years $)$ & 7 & 0 & $N S$ \\
$M / F$ & $17 / 7$ & $8 / 2$ & $N S$ \\
$p C K(I U)$ & $2,650 \pm 2,160$ & $3,490 \pm 2,060$ & $N S$ \\
$p C K t(h)$ & $13.1 \pm 4.9$ & $15.8 \pm 6.9$ & $N S$ \\
No. of diseased vessels & $1.4 \pm 0.7$ & $1.9 \pm 0.9$ & $N S$ \\
Patency of culprit lesion $(\%)$ & $80.0(16 / 20)$ & $66.7(6 / 9)$ & \\
\hline
\end{tabular}

pCK, value of peak $C K$; $p C K t$, time to peak $C K$.

Table 2 QT Interval and LV Function

\begin{tabular}{lccc}
\hline \hline Overlap & $\begin{array}{c}\text { Group A }(+) \\
(n=24)\end{array}$ & $\begin{array}{c}\text { Group B }(-) \\
(n=10)\end{array}$ & $p$ value \\
\hline$m Q T c(s)$ & $0.59 \pm 0.06$ & $0.52 \pm 0.06$ & $<0.01$ \\
$\operatorname{LEF}(\%)$ & $62.1 \pm 10.5$ & $49.3 \pm 13.5$ & $<0.01$ \\
$p C K<3,000 I U(\%)$ & $73.9(17 / 23)$ & $30.0(3 / 10)$ & $<0.02$ \\
\hline
\end{tabular}

mQTc, maximal QTc; $L V E F$, left ventricular ejection fraction; $p C K$, value of peak $C K$.

wave followed the T wave immediately, QT interval was measured to the nadir of the curve between the $\mathrm{T}$ and $\mathrm{U}$ waves. Biphasic $\mathrm{T}$ waves were measured to the time of final return to baseline. The measurement was made in the lead with the longest QTc interval (usually $\left.\mathrm{V}_{3}, \mathrm{~V}_{4}\right) !^{12}$ The maximal QTc (mQTc) and the time to maximal QTc (mQTt) were decided from these serial QTc measurements.

\section{Biochemical Analysis}

Blood samples were obtained every $4 \mathrm{~h}$ from admission until serum creatine kinase (CK) activity returned to normal levels. The value of peak CK (pCK) and the time to peak $\mathrm{CK}(\mathrm{pCKt})$ were determined on the basis of analysis of the serial changes in serum CK activity! ${ }^{3}$

\section{Cardiac Catheterization}

Four weeks after the onset, left ventriculography was performed in the 30-degree right anterior oblique projection at 25 frames/s after injecting $25 \mathrm{ml}$ of non-ionic contrast medium at a rate of $6 \mathrm{ml} / \mathrm{s}$. The left ventricular ejection fraction (LVEF) was calculated by the area-length method. Coronary angiograms were obtained on admission and/or at discharge using the Judkins technique or the trans-brachial/radial approach.

\section{Scintigraphic Evaluation}

Simultaneous dual SPECT imaging was performed 3-5 days after the onset of AMI using the method of Hashimoto et al; $1425 \%$ and $40 \%$ background subtractions were used for ${ }^{201} \mathrm{Tl}$ chloride and ${ }^{99 \mathrm{~m} T c}$ pyrophosphate cardiac images, respectively. Color tomograms were described in identical slices and regions on the green image for ${ }^{201} \mathrm{Tl}$ chloride, indicating viable myocardium, and on the red image for 99mTc pyrophoaphate, indicating necrotic tissue. The overlap, reflecting the presence of salvaged myocardium, was defined as more than one-quarter of the cardiac silhouette in at least 2 contiguous slices. Scintigraphic overlap was judged from identical slices of SPECT by visual inspection. The presence or absence of the scintigraphic overlap was determined by 2 independent investigators and resolved by consensus. There was neither subtle analysis nor inter- or intraobserver variability in the judgement of overlap.

\section{Statistics}

Data are presented as mean values \pm SD. For statistical analysis, unpaired Student's t-test was used for comparison of continuous variables between group $\mathrm{A}$ and $\mathrm{B}$, and repeated measures analysis of variance (ANOVA) was used for comparison of serial changes of QTc intervals. Multiple comparison within QTc intervals was tested with Bonferroni correction. Differences between categorical variables were examined by chi-squared test. Differences were considered statistically significant at the $\mathrm{p}<0.05$ level.

\section{Results}

Patient Characteristics (Table 1)

There were no significant differences between the 2 groups in gender, number of diseased vessels or the patency of culprit lesions.

\section{Biochemical Analysis (Table 1)}

The pCK was lower in group A $(2,650 \pm 2,160 \mathrm{IU} / \mathrm{L})$ than in group B $(3,490 \pm 2,060 \mathrm{IU} / \mathrm{L})$, but the difference between the 2 groups was not statistically significant.

However, there were $17 / 23(74 \%)$ patients with smallsized infarcts whose pCK levels were less than 3,000 IU in group A and 3/10 (30\%) in group B (p<0.02) (Table 2). The pCKt was shorter in group A $(13 \pm 5 \mathrm{~h})$ than in group B $(16 \pm 7 \mathrm{~h})$, although no differences were observed between the groups.

\section{Standard 12-Lead ECG}

A typical ECG with a prolonged QT interval and a prominent negative T wave is shown in Fig 1, and the serial changes in the QTc intervals are shown in Fig 2. In all the patients, T wave inversion was associated with QT interval prolongation. Prolongation of the QTc interval peaked $36 \mathrm{~h}$ after the onset of AMI $(0.54 \pm 0.07)$ and returned to a normal value 4 weeks later $(0.46 \pm 0.04)$. This QTc interval prolongation appeared transiently $(\mathrm{p}<0.01$ by repeated measures ANOVA with Bonferroni correction). The mQTc intervals were longer in patients with scintigraphic overlap (Fig 3). 

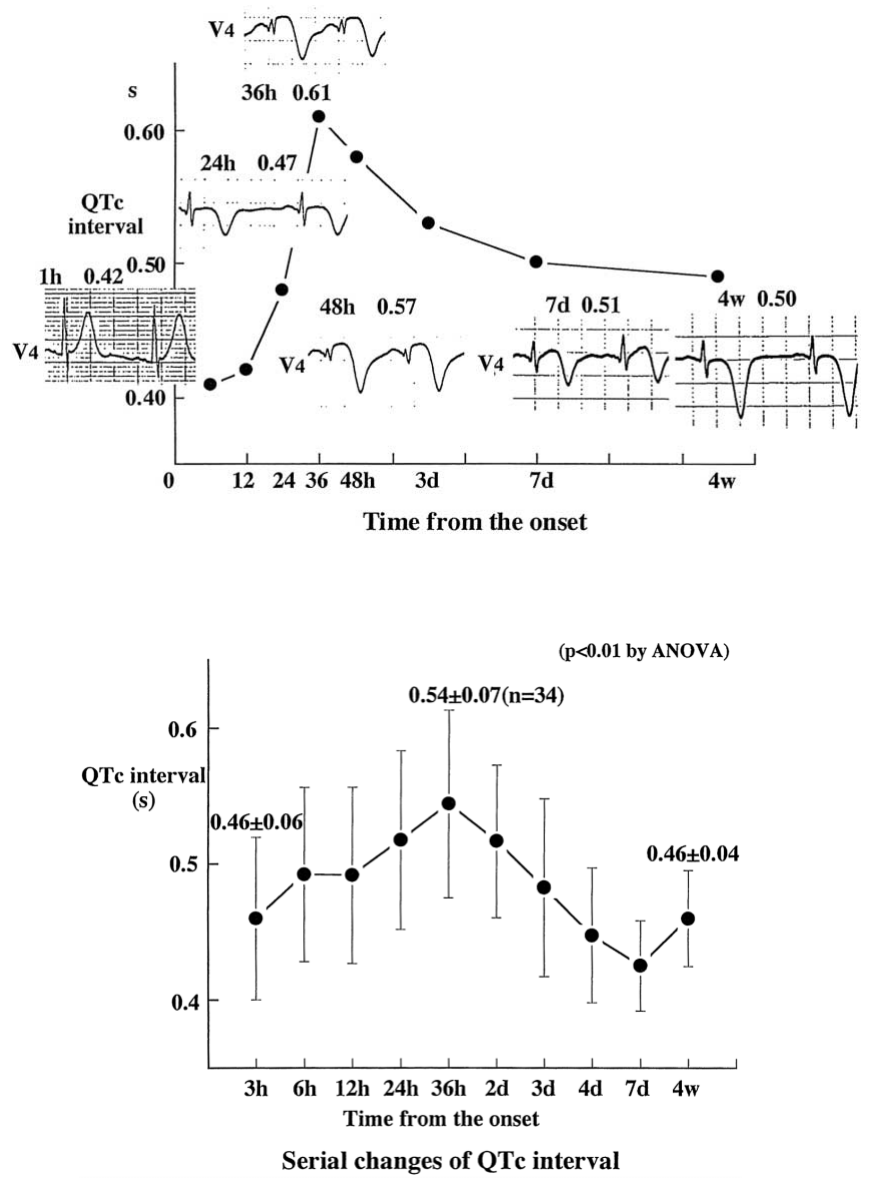

Fig 2. Serial changes in the QTc intervals. Prolongation of the QTc interval peaked $36 \mathrm{~h}$ after the onset of acute myocardial infarction (AMI) and returned to a normal value 4 weeks later $(\mathrm{p}<0.01$ by repeated measures ANOVA with Bonferroni correction). Data are presented as mean $\pm \mathrm{SD}$.

QT Intervals and Left Ventricular (LV) Function (Table 2)

The mQTc interval was $0.59 \pm 0.06 \mathrm{~s}$ in group A and $0.52 \pm$ $0.06 \mathrm{~s}$ in group B. The patients in group A showed significantly prolonged mQTc intervals compared with those in group B $(\mathrm{p}<0.01)$. Differences in the QTc intervals between the 2 groups disappeared 4 weeks after the onset of AMI. The LVEF was $62 \pm 11 \%$ in group A and $49 \pm 14 \%$ in group $\mathrm{B}$, significantly better in the former $(\mathrm{p}<0.01)$.

\section{Discussion}

Several studies support that the scintigraphic overlap phenomenon in AMI patients indicates the presence of viable myocardium, ${ }^{44,15} 99 \mathrm{mTc} / 201 \mathrm{Tl}$ overlap on dual SPECT can be used as an index for documenting early recanalization and may reflect the presence of salvaged myocardium adjacent to necrotic tissue. Hashimoto et al reported that the patients with scintigraphic overlap have a shorter interval between onset of AMI and reflow, compared with the patients without overlap $(2.5 \pm 0.8$ vs $4.8 \pm 1.3 \mathrm{~h}, \mathrm{p}<0.001))^{14}$ Our data showed that the $\mathrm{pCKt}$ was shorter in group A than in group B, although no significant differences were observed between the groups $(13 \pm 5$ vs $16 \pm 7 \mathrm{~h}, \mathrm{p}=0.216)$. Areas with overlapping of dual SPECT may contain jeopardized myocardium. 15 99m $\mathrm{Tc} / 201 \mathrm{Tl}$ overlap in the delayed image early after AMI can be used as an index for predicting
Fig 1. Typical ECG with a prolonged QT interval and a prominent negative $\mathrm{T}$ wave in $\mathrm{V}_{4}$ lead. The peak QTc interval is $0.61 \mathrm{~s}$ at $36 \mathrm{~h}$ after the onset of acute myocardial infarction (AMI).

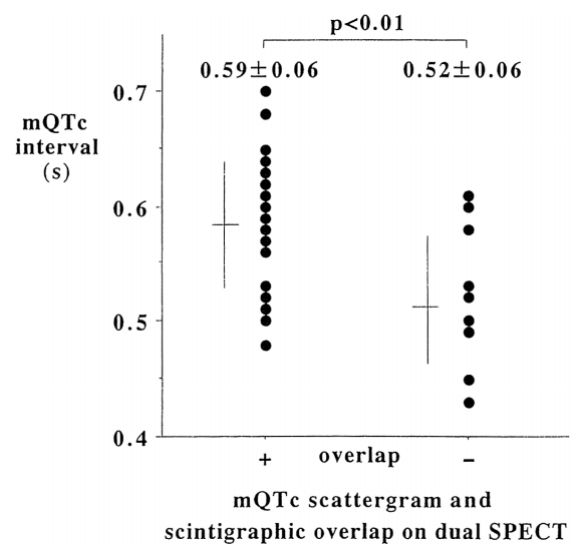

Fig 3. A maximal QTc (mQTc) scattergram is shown. The mQTc interval was $0.59 \pm 0.06 \mathrm{~s}$ in group A (scintigraphic overlap (+) group) and $0.52 \pm 0.06 \mathrm{~s}$ in group B (overlap (-) group). The patients in group A had significantly prolonged $\mathrm{mQTc}$ intervals compared with those in group $B(p<0.01)$. Data are presented as mean \pm SD.

successful early recanalization and probably viable myocardium? On ECG, T wave inversion in the left precordial leads and prominent negative $\mathrm{T}$ wave with QT prolongation in $\mathrm{V}_{3}$ or $\mathrm{V}_{4}$ reaching their peak values within 1-5 days after successful reperfusion in patients with acute coronary syndrome, may indicate reperfusion injury and the presence of myocardial stunning in the anterior wall of the left ventricle. Hirota et al reported that serial echocardiograms showed normalization of wall motion within 4 to 28 days after the onset of acute coronary syndrome. The present study demonstrated that the transient QT interval prolongation and the scintigraphic overlap on the dual SPECT imaging were closely related in patients experiencing their first anterior AMI, and also showed that the scintigraphic overlap group had a smaller infarct and better LVEF. These findings suggest that QT interval prolongation, appearing transiently in the acute phase of AMI, is associated with myocardial salvage, which is also observed on scintigraphy.

On the other hand, a consistently prolonged QT interval may indicate an increase in arrhythmias and lowering of the ventricular fibrillation threshold. Among patients with previous myocardial infarction a prolonged QTc interval indicates a 2-fold greater risk of sudden cardiac death5 Multivariate analysis of risk factors reveals that the QTc interval at discharge is of significant independent value for predicting major cardiac events after discharge from the 
hospital6 In general, delayed ventricular repolarization produces QT prolongation and may increase the vulnerable period. Such responses enhance susceptibility to ventricular arrythmias. ${ }^{16}$ However, a transient QT prolongation with prominent negative $\mathrm{T}$ waves is clinically different from the consistent QT prolongation observed with arrythmogenic substrate, because this arrythmogenic QT prolongation is consistent, not transient.

There are numerous reported causes and mechanisms for QTc lengthening: congenital, neurogenic, hypothermia, hypocalcemia, myocardial ischemia, antiarrhythmic drugs, anaphylactic reactions, post-resuscitation, cathecholamines, severe bradycardia, atrioventricular block, and unknown causes, 17-22 An ECG pattern closely resembling the QTc prolongation in AMI occurs in patients with intracranial hemorrhage ${ }^{8}$ and in patients with pheochromocytoma. The QTc prolongation in these patients is characterized by its acquired QTc interval lengthening, transient appearance and association with prominent $T$ waves inversion? 23 Several studies have shown that QT prolongation with deeply inverted $\mathrm{T}$ waves can be produced by various manipulations of autonomic innervation to the heart in animal models $20,21,24$ However, the exact mechanism of this peculiar ECG change in AMI patients is still uncertain.

Lead selection for the measurement of the QT interval is important. Measurements of the QT interval in precordial unipolar leads are more precise than in bipolar limb leads, because more subtle and much smaller changes of the QT interval and $\mathrm{T}$ wave inversion are canceled and masked in bipolar leads ${ }^{2}$ For these reasons, patients with inferior AMI were excluded from this study.

Patency of the culprit coronary lesion did not relate to scintigraphic overlap in this study. Of the 29 patients undergoing emergency coronary angiography, recanalization of the culprit lesion failed in 7 and 5 of these had rich collaterals. In total, 27/29 (93.1\%) of patients undergoing emergency coronary angiography reestablished coronary flow to the jeopardized myocardium; therefore, coronary patency of the lesions did not affect statistically the presence of scintigraphic overlap.

\section{Study Limitations}

The study subjects were consecutively entered into the study, but because of the importance of lead selection for QT interval measurement and the acute phase scintigraphic study only $22 \%$ (34/154) were enrolled. Thus the subgroup subjected to the various analyses became very small. As the judgement of scintigraphic overlap was not quantitative, the presence of the overlap as assessed on the identical slices in the dual SPECT was obvious and did not require a more detailed analysis.

Although there was a significant difference in age between the groups, it was accidental that all the 7 patients older than 70 years old belonged to group $\mathrm{A}$, and that this group of patients were older than the patients in group B. There was no evidence that age was an independent factor for scintigraphic overlap.

\section{Conclusions}

The present study demonstrated that transient QT interval prolongation and scintigraphic overlap on the dual $(99 \mathrm{mTc}$ pyrophosphate/201 Tl chloride) SPECT imaging are closely related in patients experiencing their first anterior AMI, and also showed that the scintigraphic overlap group had a smaller infarct and better LVEF. These findings suggest that QT interval prolongation, which appears transiently on ECG in the acute phase of AMI, indicates the presence of salvaged myocardium observable on scintigraphy.

\section{References}

1. Krasnoff SO: The duration of the Q-T intrval in myocardial infarction. Am Heart J 1950; 39: 523-531

2. Cinca J, Figueras J, Tenorio L, Valle V, Trenchs J, Segura R, et al: Time course and rate dependence of Q-T interval changes during noncomplicated acute transmural myocardial infarction in human beings. Am J Cardiol 1981; 48: 1023-1028

3. Surawicz B: ST-segment, T-wave, and U-wave changes during myocardial ischemia and after myocardial infarction. Can J Cardiol 1986; SupplA: 71A-84A

4. Hirota Y, Kita Y, Tsuji R, Handa H, Ishii K, Yoneda Y, et al: Prominent negative $\mathrm{T}$ waves with QT prolongation indicate reperfusion injury and myocardial stunning. J Cardiol 1992; 22: 325-340

5. Schwartz PJ, Wolf S: QT interval prolongation as predictor of sudden cardiac death in patients with myocardial infarction. Circulation 1978; 57: $1074-1077$

6. Ahnve S, Helmers C, Lundman T, Rehqvist N, Sjogren A: QTc interval in acute myocardial infarction: First-year prognostic implications. Clin Cardiol 1980; 3: 303-308

7. Dilsizian V, Bonow RO: Current diagnostic techniques of assessing myocardial viability in patients with hibernating and stunned myocardium. Circulation 1993; 87: 1-20

8. Surawicz B, Knoebel S: Long QT: Good or bad? J Am Coll Cardiol 1984; 4: 398-413

9. Sakata K, Yoshida H, Ono N, Ohtani S, Mori N, Yokoyama S: Implications of delayed image on simultaneous thallium-201/technetium-99m pyrophosphate dual emission computed tomography early after acute myocardial infarction. Jpn Circ J 1993; 57: 27-36

10. Bazzet HC: An analysis of the time-relations of electrocardiograms. Heart 1920; 7: 353-370

11. Lepeschkin E, Surawicz B: The measurement of the Q-T interval of the electrocardiogram. Circulation 1952; 6: $378-388$

12. Cowan JC, Yusoff K, Moore M, Amos PA, Gold AE, Bourke JP: Importance of lead selection in QT interval measurement. Am J Cardiol 1988; 61: 83-87

13. Sobel BE, Bresnahan GF, Shell WE, Yoder RD: Estimation of infarct size in man and its relation to prognosis. Circulation 1972; 46: 640648

14. Hashimoto T, Kambara H, Fudo T, Tamaki S, Takatsu Y, Hattori R, et al: Significance of technetium-99m/thallium-201 overlap on simultaneous dual emission computed tomography in acute myocardial infarction. Am J Cardiol 1988; 61: 1181-1186

15. Isoda $\mathrm{H}$, Itagaki $\mathrm{Y}$, Nomura $\mathrm{N}$, Urushida $\mathrm{T}$, Naitou $\mathrm{A}$, Watanabe $\mathrm{A}$, et al: Usefulness of dual SPECT with Tc-99m pyrophosphate and Tl201 to predict further events after acute myocardial infarction with single-vessel coronary artery disease. Clin Nucl Med 1999; 24: 227 231

16. Han J, Moe GK: Nonuniform recovery of excitability in ventricular muscle. Circ Res 1964; 14: 44-60

17. Shen AC, Jennings RB: Myocardial calcium and magnesium in acute ischemic injury. Am J Pathol 1972; 67: 417-440

18. Shen AC, Jennings RB: Kinetics of calcium accumulation in acute myocardial ischemic injury. Am J Pathol 1972; 67: 441-452

19. Mehta D, Warwick G, Goldberg MJ: QT prolongation after ampicillin anaphylaxis. Br Heart J 1986; 55: 308-310

20. Browne KF, Zipes DP, Heger JJ, Prystowsky EN: Influence of autonomic nervous system on the Q-T interval in man. Am J Cardiol 1982; 50: $1099-1103$

21. Murayama M, Mashima S, Shimomura K, Takayanagi K, Tseng Y, Murao S: An experimental model of giant negative T wave associated with QT prolongation produced by combined effect of calcium and isoproterenol. Jpn Heart J 1981; 22: 257-265

22. Abildskov JA: Adrenergic effects on the QT interval of electrocardiogram. Am Heart J 1976; 92: 210-216

23. Stenstrom G, Swedberg K: QRS amplitude, QTc intervals and ECG abnormalities in pheochromocytoma patients before, during and after treatment. Acta Med Scand 1988; 224: 231-235

24. Murayama M, Harumi K, Mashima S, Shimomura K, Murao S: Prolongation of ventricular action potential due to sympathetic stimulation. Jpn Heart J 1977; 18: 259-265 